Historic, archived document

Do not assume content reflects current scientific knowledge, policies, or practices. 



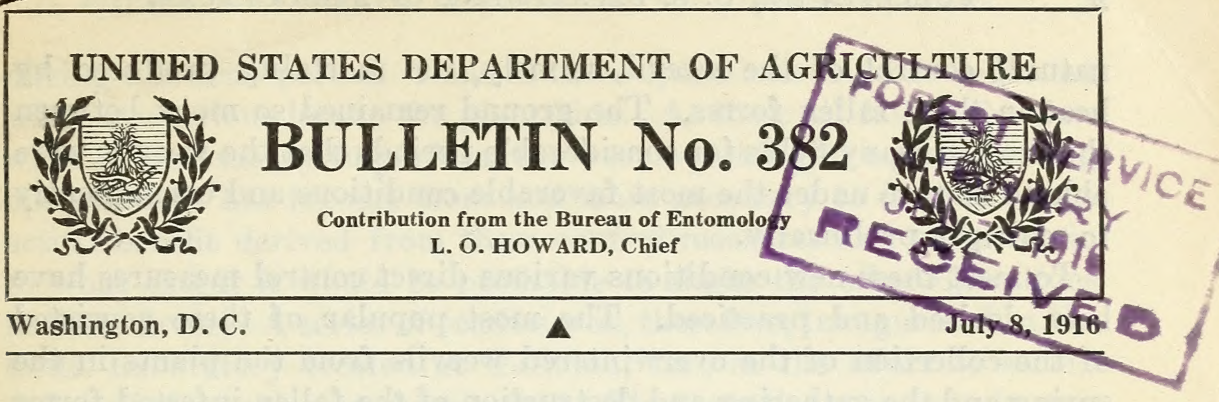

\title{
COTTON BOLL-WEEVIL CONTROL IN THE MISSISSIPPI DELTA, WITH SPECIAL REFERENCE TO SQUARE PICK- ING AND WEEVIL PICKING.
}

\author{
By B. R. COAD, \\ Entomological Assistant, Southern Field Crop Insect Investigations.
}

\section{INTRODUCTION.}

In devising measures for the control of the boll weevil the experience of the Bureau of Entomology has shown that those which are practicable in one region do not necessarily apply in another. The conditions vary according to climate, topography, and systems of agriculture. Each locality offers peculiar conditions, but striking differences occur between the cotton regions of Texas and of the delta of Louisiana and Mississippi. These varying conditions have led to the development of rather distinct methods of control of the weevil, as applied to these two regions.

During the progress of the Mexican cotton boll weevil northward and eastward across the State of Texas, a combination of control measures which was reasonably effective in limiting the damage to the cotton crop was devised and adopted. These measures were largely of a more or less indirect nature, such as planting early maturing varieties, frequent shallow cultivation, wide spacing of the plants to allow the surıshine to reach the fallen squares, etc. Largely owing to the comparatively dry climate and the exceedingly high mortality of the weevil stages in the fallen forms, produced by the hot sunshine, these measures generally sufficed for that region. When the weevils invaded the Delta region of the Mississippi River, in the States of Louisiana and Mississippi, however, it was found that weevil control was complicated by new conditions. The extremely heavy rainfall and high humidity prevailing in the Delta region, together with the rank vegetative growth typical of the cotton plants there, combined to reduce greatly the most important factor in the

\footnotetext{
NoTE.-This bulletin is intended to give practical advice to the cotton raisers of the
} Mississippi Delta on the subject of controlling the boll weevil. 
natural control of the weevil, namely, the mortality produced by heat in these fallen forms. The ground remained so moist between therows in many fields for considerable periods that the weevils were able to mature under the most favorable conditions and consequently to multiply prolifically.

To meet these new conditions various direct control measures have been devised and practiced. The most popular of these consisted of the collection of the orerwintered weevils from the plants in the spring and the gathering and destruction of the fallen infested forms from the ground. These operations are commonly termed "weevil picking" and "square picking," respectively. They are based on the fact that the most critical period in the yearly cycle of the weevil and the time at which its numbers reach the lowest ebb is in the spring when the comparatively few survivors of the winter are emerging. In an average season these overwintered weevils are relatively scarce, and it is not until their progeny begin to mature and multiply that the actual severe damage to the cotton is produced. Owing to the very high fecundity of the individual females, each overwintered weevil destroyed early in the spring means the elimination of an enormous number of potential progeny in the later generations, and, in the same way, the collection of the immature stages of the weevils of the first-bred generation in the fallen forms not only reduces the weevil abundance by the actual number collected but also retards further multiplication. Because of these facts a number of cotton planters have considered it a paying proposition to incur a considerable expense per acre to destroy these early weevils. It was found, however, that the results secured by the different planters practicing these control measures varied widely and their conclusions as to the actual benefit derived were equally diverse. Many claimed very positive gains while many of their neighbors operating under much the same conditions could see no benefit from the measures and considered the expense thus incurred an absolute loss.

Another factor enters into the problem and further complicates matters. This is the question of labor supply. Under the conditions at present prevailing in the Delta the available labor, during the months of May and June, is always more or less short of the labor needed. In addition to this, one very important effect of the weevil on the economic system of this region has been the forcing of diversified farming instead of the old one-crop system. The new crops most generally adopted were corn and oats. As a result the labor crisis during the spring period has become even more acute. Not only does the cotton require cultivating and hoeing, but it is also necessary to cultivate and hoe the corn and cut, shock, haul, and thrash the oats 
during this same period. None of these operations could be neglected without a serious loss to the plantation. As these all fall at the time when it is necessary to perform the weevil-picking or square-picking operations it has become more and more necessary to determine the actual benefit derived from these control measures and to ascertain to what extent it would be profitable to slight the other operations in their favor. A series of studies was, therefore, inaugurated at the Delta Laboratory located at Tallulah, La., in the effort to secure definite information on these points. These studies were largely conducted on an experimental basis, but their results were checked by observations on the plantation use of the different control measures. The following is a brief consideration of the points brought out by these studies.

\section{SQUARE PICKING.}

The first of the studies consisted of plat tests on the effect of picking only the fallen forms during the spring. The first picking was made as soon as the fallen forms had reached a considerable number and still before the weevils had started to emerge from them. As the emergence of the weevil from hibernation was exceedingly late during the season when this test was conducted (1915), it did not prove necessary to conduct this first picking until June 16. Of course this date of picking would vary widely with the season, and in a year of normal emergence it would undoubtedly be much earlier. Following this the plat was carefully picked over every 7 days until July 14, a total of five pickings, extending over a period of 28 days. During this time 42,672 forms per acre were collected. In actual bulk this equaled about 42 gallons per acre. The method of picking used was the simplest possible. Mixed negro laborers were provided with sacks for holding the forms and were sent down the rows to gather all forms from the ground by hand. The picking was carefully supervised in order to make sure that the collections were thorough.

The weevil infestation in these plats was followed carefully throughout the season and it was soon found that the infestation in the picked plat was showing a very decided effect from the operation. For example, on July 6, 18 per cent of the squares in the picked plat were infested, while 44 per cent were infested in the untreated check plat. On July 13, the percentages were 37 and 63 , respectively. In fact all observations consistently demonstrated that the square collection was reducing the weevil infestation within the treated plat. Of course the final criterion determining the effect of the operation was the production, and it was found that the picked plat produced 23 per cent more seed cotton per acre than the check. However, this 
gain in yield must not be considered as being net profit, since there are certain expenses to be charged against the value of this increased production. These are the actual labor involved in the control operation and the effect of diverting the labor from the usual operations to those of weevil control.

Careful studies were made on the labor involved in these square pickings and the figures secured from the experimental tests were also checked under conditions more closely approximating those of plantations. From these studies it was found that the average labor per acre involved in the pickings ranged from about 4 hours for the first to about 24 hours for the fifth. The general average of all the pickings was slightly over 11 hours per acre per picking. As the labor day in the Delta section is usually of about 12 hours during the spring, this indicates that the pickings would average about 1 day's labor per acre, or a total of 5 days for the five pickings. As the greater part of the picking is done by women and children, this labor probably has a value of not more than 50 cents per day on the average. This would make the five pickings cost about $\$ 2.50$ per acre on a wage basis. Of course this labor will vary greatly with the locality, field, and seasonal conditions, as these factors will determine the number of fallen forms present to be picked. Heavy infestation, producing a large number of fallen infested forms, will, of course, require much more labor per acre to control, while a lighter infestation, particularly on thin, sandy land, where the square formation is not so profuse, will result in comparatively few forms to be collected, and the labor required will be lessened. Under certain conditions of soil and climate there is frequently a very heavy shedding of uninjured forms. Of course these can not be distinguished from the infested forms when on the ground, and must be gathered. This condition occasionally becomes so pronounced that it greatly increases the labor involved in picking.

The time interval between pickings in this test ( 7 days) was selected arbitrarily, but it is probably about the most satisfactory period. This gives an interval sufficiently short to prevent any considerable weevil emergence from the fallen forms between pickings and is still about as long as can be safely allowed. The number of pickings must depend entirely on the conditions prevailing. The object of the number utilized in this test was to cover the period from the first falling of squares in considerable numbers to the time when the work becomes too bulky to handle. As previously mentioned, in an ordinary year the operation would probably start earlier than was necessary in 1915 , but, owing to the rapid increase in the labor required during the later pickings, it would probably not be profitable to give more than four pickings under ordinary 
conditions. If any benefit is going to be derived, it should be secured during this period, and the cost of the operation will be sufficiently low to allow a reasonable margin for profit. It seems hopeless to expect to prevent all weevil multiplication in the field, regardless of how thoroughly the picking operations are conducted, and the best that can be hoped for is to retard the time when the practically complete infestation of squares is reached, thus allowing a slightly longer period for the formation of fruit and the safe maturing of the bolls which have already been set.

The disposal of these infested forms is an important item. Based on the conditions which prevailed in the more western territory, where the parasitic control of the weevil is a considerable item and where smaller amounts of forms are collected, it was recommended that they be placed in screen cages, instead of actually destroying them, thus allowing the emergence and escape of the weevil parasites in these forms and still retaining for later destruction the weevils maturing from them. In the Delta, however, the conditions are so different that this recommendation is not advisable. Parasitic control of the weevil in the Delta is generally so low that it is of little importance, and therefore comparatively few parasites would be saved by this means. In fact, unless rather elaborate and expensive precautions were taken to prevent the weevils' escape from these cages it seems probable that a sufficient number of weevils would be released to more than offset the parasites saved. This consideration is further emphasized by the carelessness of the negro laborer. In addition, the quantity of forms handled in the Delta is so great that the expense of providing cages for their disposal is practically prohibitive. It has already been shown that in the plat tests of 1915 an average of 42 gallons of forms were collected per acre. When it is considered that many of the Delta planters reckon their cotton acres by the hundreds and even by the thousands, it is easy to see what an enormous task it would be to provide screen cages for these forms. In view of these facts it seems advisable to dispose of these forms in the quickest and most effective manner possible. This may be done quite easily by burning or burying them.

\section{WEEVIL PICKING.}

There are a number of different methods of collecting the adult weevils from the cotton, but it is probably best to consider only those most prevalent in the Delta. In earlier years practically the only method practiced was what is now termed "hand picking." In following this method the laborers were each given a box or a bottle and they depended entirely upon being able to see and capture the adult 
weevils on the plants. This method was exceedingly slow and laborious and, owing to the large number of weevils actually overlooked, and the additional number escaping by "possuming" and falling to the ground upon the first disturbance of the plant, this method was not very effectual. Within the last few years, however, a semimechanical method of collection has been devised by some of the Delta planters and its use has spread rapidly. This is what is commonly termed the "bag-and-hoop," or "hoop-and-sack" method of collection. It consists of shaking the plants into a sack, the mouth of which is held open by a barrel hoop. This method proved to be much more effective and less expensive than hand picking.

To determine the relative efficiency of these two methods of weevil collection a number of comparative tests were conducted. These show the hand picking to require four times as long as the bag-andhoop, while the latter collected more than twice as many weevils as the hand picking from the same area. In addition to this, in the course of the weevil collection with the bag-and-hoop a large number of infested forms are gathered, thus making the operation in reality a combination of weevil picking and square picking. Thus it can readily be seen that there is no question of the great superiority of the bag-and-hoop method over hand picking.

The apparatus required for the bag-and-hoop collections is the simplest possible. A burlap seed sack with a barrel hoop some 24 inches in diameter sewn into its mouth is all that is necessary. A tub or barrel of water with a small amount of kerosene on its surface may be placed on the turnrow and the bags emptied into it about every second row.

It was found that there was considerable difference in the results secured from the different methods of handling this bag-and-hoop. Comparative observations have shown the following to yield the best results: The bag should be placed against the base of the cotton stalk with as little disturbance as possible. Then the plant should be gently bent well into the mouth of the bag and shaken several times rather sharply from side to side, that is, at right angles to the length of the bag instead of back and forth into its mouth. It was found that there was considerable difference in the weevils collected when these two methods of shaking the plant were compared. As a result of shaking the plant lengthwise of the bag a number of weevils are evidently thrown away from the bag instead of into it, while other weevils actually thrown into the bag strike against the hanging back and bounce out again. On the other hand, when the plant is shaken across the sack, all weevils falling from it are retained.

More elaborate devices resembling the bag-and-hoop in principle were tested, but it was found that none of these was as efficient as 
the simple form just described and that all possessed the additional disadvantage of being more expensive to make.

Observations were made to determine the time required per acre for the operation of the bag-and-hoop, and it was found to vary widely with the individual laborer, but the general range was found to be from 1 to 2 acres per hand per day. Of course the operation would be more rapid during the early pickings when the plants are small and weevils are rather scarce. The figures secured, however, seem to indicate that from 1 to $1 \frac{1}{2}$ acres per laborer per day is the best average that can be expected throughout the picking season. On a day-wage basis this would mean an average expenditure of some 40 to 60 cents per acre for each picking, and if the pickings were continued very late into the season this expense would be considerably increased.

The time interval between pickings which will yield the best results is still open to question, but it seems advisable to make it shorter than that between square pickings in order to reduce the time for square puncturing allowed the weevils, and also to reduce the number of infested forms falling to the ground between pickings, thus securing the benefit of both square picking and weevil picking. The studies to date seem to indicate that better results will be secured from several pickings given early in the season with a short time interval than where the same number of pickings are extended over a longer period by making the time interval a week or more. In fact, when the labor supply is not sufficient to allow this intensive treatment of all of the cotton it seems probable that better net results would be secured by concentrating the labor on only a portion of the crop and allowing the remainder to go untreated. In the case of cotton worked by wage labor the control measures could be concentrated on certain cuts, while in a case of tenant cotton the thorough and consistent picking of a portion of a cut would probably be more profitable than scattering the same amount of labor over the entire cut, in a series of more or less irregular and haphazard pickings. This concentration of effort, however, would not apply in a season of exceedingly heavy weevil infestation when the available food supply on the near-by untreated cotton would soon be exhausted and the weevils would migrate into the picked cotton in search of food. Except under these conditions, however, the early season interfield movement of weevils is apparently sufficiently slight to allow their control within a comparatively small area.

\section{GENERAL CONSIDERATIONS.}

The foregoing discussion has been devoted to the consideration of the best methods of picking weevils and squares, and the figures have been based on a day wage scale. There now remains to be considered 
the application of these facts and figures to plantation conditions. In the first place there is little or no picking on a day wage basis, but it is practiced under the tenant system where no actual cash outlay is required and the only expense of the operations is that incurred by the detrimental effect produced on either the cotton or some other crop because of taking the labor from its care and utilizing it in these weevil control measures. Consequently, the question is just how much the planter can afford to slight the other operations in order to pick his squares or weevils. Studies on the increased yields produced by these control measures have shown that there is a very definite advantage. However, very little neglect of the cultural operations may produce a loss amply sufficient to more than offset any benefit derived from the reduction of the weevil infestation. For this reason it seems generally inadvisable to practice these control measures except in the presence of an abundance of labor.

Because of this complication with the labor supply the greatest desideratum at present is the perfection of a mechanical means of weevil picking which will be as effective as the bag-and-hoop method and still will allow the handling of a considerable number of acres per day per hand. Several mechanical devices were tested in comparison with the bag-and-hoop and, while none of them was as efficient as the latter method, one or two gave some promise of satisfactory results with further improvements in their construction. It should be stated that there are a number of serious problems to be met by a mechanical picker, which make it still doubtful as to whether a satisfactory one can be devised. In the first place the question of interruption of operations by rainy weather is a serious problem. A number of successive rainy days resulting in continually muddy fields produces the best possible conditions for weevil multiplication and thus necessitates even more strenuous efforts for control, but the same conditions make it difficult to operate mechanical pickers in the field. Such weather conditions are met with practically every spring in the Delta. The necessity for drainage in this region causes the cotton to be planted and worked on "ridges." This raising of the plants above the middle of the rows interferes seriously with the operation of many mechanical pickers. In addition to this, as long as the present system of laying off and planting rows is followed there will always be more or less crooked rows and the distances between the rows will vary considerably. This condition presents another obstacle to mechanical pickers, particularly those taking two rows at a turn. Still another obstacle is the difficulty in operating many of these machines in irregular, stumpy land such as is found on some parts of almost every plantation in the Delta. These fields are the ones which have been cleared only recently and 
with proper protection from the weerils would make far better cotton crops than the land which has been in cultivation for a longer period. Considering these obstacles to be orercome and the degree of efficiency in weeril collection which must be dereloped by a mechanical picker, it is easy to see that there will be great difficulty in developing a satisfactory one.

One factor in the relation of these weeril-picking measures to the plantation complex is the effect upon the labor itself. On many plantations it is desirable to have the laborer's conduct some direct control measures in order to encourage them to rork the crop thoroughly. In such cases the bag-and-hoop method seems to satisfy the needs rery well. The laborers can capture a considerable number of weerils and the fact that they are actually destroying these weevils often seems to encourage them greatly. In fact, a number of planters who practice this control measure state that they do not consider that they are deriring any direct benefit from the reduction in weevil infestation, but that the operation is worth while because of its beneficial effect upon the morale of their labor.

\section{SUMMARY AND CONCLUSIONS.}

Plat tests of five square pickings at seven-day time intervals gare an increased yield of 23 per cent over the check.

Tests of seven weevil pickings with the bag-and-hoop indicated similar results.

The seasonal conditions obtaining during the course of the experiments described in this bulletin have been referred to; it is possible that different seasonal conditions might yield different results.

Comparative observations on different methods of collecting weevils demonstrated the great superiority of the bag-and-hoop over hand picking so definitely that there should be no question as to which method to follow.

The margin of profit to be derived from these two control measures seems to be too slight to allow their operation on a wage basis. For this reason the only condition under which they should be attempted is on tenant cotton where the work can be performed without any direct outlay for labor.

Owing to the shortage of labor in the Delta these operations are very likely to interfere seriously with the regular plantation work and thus cause a loss more than sufficient to offset any benefit derived from them. In such cases it is not advisable to attempt to pick either squares or weevils.

In case it is necessary to choose between a cultiration and a weevil or square picking, cultivate. 
If, after considering the foregoing points, it seems advisable to practice either of these control measures, the following seem to be the best methods:

Square picking.-A time interval of about seven days between square pickings seems advisable.

The first picking should be made within a week of the time when the squares start to fall in considerable numbers.

It is not likely to prove profitable to pick squares more than four or fire times.

The squares should be disposed of as soon as possible after collection by burning or burying.

Weevil picking.- The most satisfactory method of weevil picking now known is the bag-and-hoop.

The first picking should be made as soon as the weevils are sufficiently abundant to make the operation worth while. This is likely to be about the time the plants start squaring or soon thereafter, although in exceptional cases it is not necessary to pick until considerably later.

Following this the pickings should be made as frequently as possible-twice a week, if practicable.

It is not likely to prove profitable to make more than four to six pickings at the most.

Of these two measures the bag-and-hoop is likely to prove the more profitable under usual conditions and is really the easiest and simplest method to practice. 


\title{
PUBLICATIONS OF U. S. DEPARTMENT OF AGRICULTURE RELATING TO THE BOLL WEEVIL.
}

\author{
AVAILABLE FOR FREE DISTRIBUTION.
}

Cotton Improvement Under Weevil Conditions. (Farmers' Bulletin 501.)

The Boll Weevil Problem. (Farmers' Bulletins 512.)

Recent Studies of the Mexican Cotton Boll Weevil. (Department Bulletin 231.)

Relation of the Wild Cotton Weevil to Cotton Planting in the Arid West. (Department Bulletin 233.)

Studies on the Biology of the Arizona Wild Cotton Weevil. (Department Bulletin 344.)

Studies of the Mexican Cotton Boll Weevil in the Mississippi Valley. (Department Bulletin 358.)

Most Important Step in Control of Boll Weevil. (Entomology Circular 95.)

Hibernation and Development of Cotton Boll Weevil. (Entomology Bulletin 63, Pt. I.)

\section{FOR SALE BY SUPERINTENDENT OF DOCUMENTS.}

Mexican Cotton Boll Weevil. (Entomology Circular 6, English Edition.) Price, 5 cents.

El Picudo ó Gorgojo Mexicano de la Capsula del Algodón [Mexican Cotton Boll Weevil]. (Entomology Circular 6, Spanish Edition.) Price, 5 cents.

Mexican Cotton Boll Weevil. (Entomology Circular 14, English Edition.) Price, 5 cents.

Same, Spanish Edition. Price, 5 cents.

Mexican Cotton Boll Weevil. (Entomology Circular 18.) Price, 5 cents.

Most Important Step in Cultural System of Controlling Boll Weevil. (Entomology Circular 56.) Price, 5 cents.

What Can Be Done in Destroying Cotton Boll Weevil During Winter. (Entomology Circular 107.) Price, 5 cents.

Status of Cotton Boll Weevil in 1909. (Entomology Circular 122.) Price', 5 cents.

Annotated Bibliography of Mexican Cotton Boll Weevil. (Entomology Circular 140.) Price, 5 cents.

Movement of Mexican Cotton Boll Weevil in 1911. (Entomology Circular 146.) Price, 5 cents.

Movement of Cotton Boll Weevil in 1912. (Entomology Circular 167.) Price, 5 cents.

Mexican Cotton Boll Weevil. (Entomology Bulletin 45.) Price, 25 cents.

Mexican Cotton Boll Weevil, Revision and Amplification of Bulletin 45, to Include Important Observations Made in 1904. (Entomology Bulletin 51.) Price, 15 cents.

Proliferation as Factor in Natural Control of Mexican Cotton Boll Weevil. (Entomology Bulletin 59.) Price, 15 cents.

Papers on Cotton Boll Weevil and Related and Associated Insects. (Entomology Bulletin 63, 7 pts.) Price, 15 cents. 
Notes on Biology of Certain Weevils Related to Cotton Boll Weevil. (Entomology Bulletin 63, Pt. II.) Price, 5 cents.

Ant Enemy of Cotton Boll Weevil. (Entomology Bulletin 63, Pt. III.) Price, 5 cents.

I'redatory Bug Reported as Enemy of Cotton Boll Weevil. (Entomology Bulletin 63, Pt. IV.) Price, 5 cents.

Studies of Parasites of Cotton Boll Weevil. (Entomology Bulletin 73.) Price, 10 cents.

Some Factors in Natural Control of Mexican Cotton Boll Weevil. (Entomology Bulletin 74.) Price, 15 cents.

Hibernation of Mexican Cotton Boll Weevil. (Entomology Bulletin 77.) Price, 25 cents.

Insect Enemies of Cotton Boll Weevil. (Entomology Bulletin 100.) Price, 15 cents.

Insects Affecting the Cotton Plant. (Farmers' Bulletin 47.) Price, 5 cents.

Information Concerning the Mexican Cotton Boll Weevil. (Farmers' Bulletin 189.) Price, 5 cents.

Controlling the Boll Weevil in Cotton Seed and at Ginneries. (Farmers' Bulletin 209.) Price, 5 cents.

The Use of Paris Green in Controlling the Cotton Boll Weevil. (Farmers' Bulletin 211.) Price, 5 cents.

The Control of the Cotton Boll Weevil. (Farmers' Bulletin 500.) Price, 5 cents. 

